Robertson, G. J., AND R. I. Goudie. 1999. Harlequin Duck (Histrionicus histrionicus). In F. Gill and A. Poole [EDS.], The birds of North America, No. 466. Birds of North America, Inc., Philadelphia, PA.

Salomonsen, F. 1968. The molt migration. Wildfowl 19:5-24.
ThOMPSON, J. E. 1992. The nutritional ecology of molting male Canvasbacks (Aythya valisineria) in central Alberta. M.Sc. thesis, Univ. Missouri, Columbia, MO.

Thompson, J. E., AND R. D. Drobney. 1997. Diet and nutrition of male Canvasbacks during postreproductive molts. J. Wildl. Manage. 61:426-434.

\title{
RELATIONSHIP BETWEEN TAIL COLOR PATTERN AND REPRODUCTIVE SUCCESS, MATE ACQUISITION AND NEST PREDATION IN RUFOUS BUSH CHATS ${ }^{1}$
}

\author{
Fernando Alvarez \\ Estación Biológica de Doñana, C.S.I.C., Apartado postal 1056, E-41080 Sevilla, Spain, \\ e-mail: alvarez@.ebd.csic.es
}

\begin{abstract}
Rufous Bush Chats (Cercotrichas galactotes) show a conspicuous tail color pattern consisting of terminal white and subterminal black patches which are shown in tail display during nest defense, aggression, and courtship. Multiple linear regression of visual tail features of males showed that in the two years of study, birds with higher bilateral symmetry in the black patches attained higher seasonal reproductive success, mated earlier in the season, and their nests were less likely to be depredated. In one year, birds with greater white terminal patches also attained higher reproductive success and their nests were less likely to be depredated, and in the other year birds with longer tails paired earlier. I suggest that these tail features have an effect on reproductive success by facilitating early pairing and/or by diminishing nest predation.
\end{abstract}

Key words: Cercotrichas galactotes, distraction displays, mate acquisition, reproductive success, $R u$ fous Bush Chats, tail color pattern.

Male plumage color pattern in passerines has an effect on reproduction, either through female choice (Andersson 1994) and male contest competition (Pärt and Qvarnström 1997), or as a result of distraction displays towards potential predators during nest defense (Baker and Parker 1979).

The visual features affecting reproduction often are situated in the tail, which is displayed towards recipients. Visual tail features may consist of tail length (Andersson 1982, Møller 1988, Barnard 1990), symmetry of tail feathers (Møller 1992), tail damage (Fitzpatrick and Price 1997), or size of tail spots (Kose and Møller 1999).

During nest defense, antagonistic interactions, and courtship, Rufous Bush Chats (Cercotrichas galacto-

\footnotetext{
${ }^{1}$ Received 3 June 1999. Accepted 29 February 2000 .
}

tes) cock their tail and move it up and down, either closed or more or less spread, sometimes accompanied with a simultaneous jerking of both wings (López 1983, Cramp 1988, Keith et al. 1992). In this way the characteristics of the conspicuous terminal white patches and adjacent black patches of the rust-colored tail feathers are shown (Fig. 1).

When chicks are found in the nest, and apparently more often as they grow older, or when a potential predator approaches the nest too closely, parent Rufous Bush Chats use a tactic of distraction (Cramp 1988), approaching the potential predator and flying away from it and from the nest, tail displaying while facing the predator, sometimes at less than $1 \mathrm{~m}$. At a distance, the birds are usually not distinct from the background, to become visible when displaying the conspicuous tail pattern.

Although the birds display towards any kind of predator, including humans (pers. observ.), of all potential nest predators in the study area, the Common Cuckoo (Cuculus canorus) is the only species with sufficient visual acuity to pay special attention to color patterns, commonly parasitizing (average of $27 \%$ of nests, Alvarez 1994a) and depredating (Alvarez 1994b) Rufous Bush Chat nests.

In aggressive situations, tail display (also while facing the opponent) usually accompanies threats, chases, and attacks. During courtship, it accompanies approaches, chases, and copulation attempts by the male, and the male displays either facing towards or away from the recipient female (the pattern is visible from both sides of the tail feathers) (Cramp 1988).

Rufous Bush Chats arrive to their breeding quarters in southern Spain during April and early May and remain until August and September (pers. observ.). Males arrive before females, establish mating territories which are often found in vineyard fields, and they sing from fixed posts (Cramp 1988, Alvarez 1996, 1997). Both sexes build a nest, but only the female 


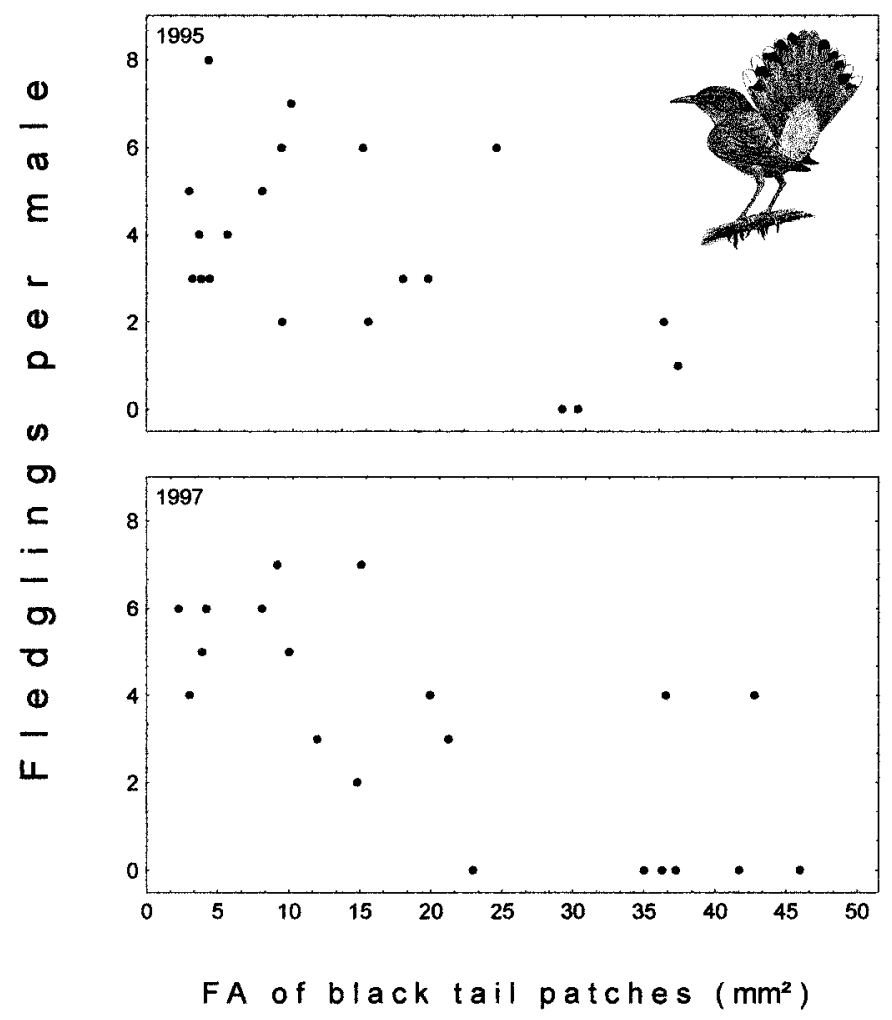

FIGURE 1. Fluctuating asymmetry (FA) of subterminal tail black patches and number of fledglings produced by each Rufous Bush Chat male in 1995 and 1997.

incubates. Social monogamy is the norm, and the pair remains together for the season. Second clutches are common, and replacement clutches are frequent, due to predation (average of $39 \%$ in a 6 -year period in the study area), so that up to six successive nesting and laying attempts by the same pair after nest predation have been observed.

It is not possible to distinguish 1-year-old birds from older birds, and there is no information available on differences in the pattern of the tail patches or in any other feature between ages.

The aim of this study was to estimate the relationship between the visual tail features and reproductive success, date of mate acquisition, and incidence of nest predation in Rufous Bush Chats.

\section{METHODS}

The study area, about $20 \mathrm{~km}$ to the southeast of the city of Seville, Spain $\left(37^{\circ} 9^{\prime} \mathrm{N}, 2^{\circ} 14^{\prime} \mathrm{W}\right)$, is mostly used for intensive vineyard agriculture (vine stocks $1-1.5 \mathrm{~m}$ high, where Rufous Bush Chats build their nests), with orchards, interspersed fruit trees, and areas of kitchen gardens and vegetable growing. The climate is Mediterranean, with dry and hot summers, wet autumns and springs, and mild winters.

The study was undertaken during the reproductive seasons of 1995 and 1997 and extended from the mid- dle of April to the end of August. As males arrived to the breeding area, and before pairs were formed, they were attracted toward a recorded song and a stuffed Rufous Bush Chat decoy and caught in mist nets. Immediately after being captured, they were measured and banded with a steel ring and a unique combination of two plastic rings, and all information on their tail features was obtained. Body and tail features were remeasured by one of two persons, different from the one who took the first measure. Females are very secretive in the early phases of reproduction and were therefore not captured. Of the 28 and 35 males caught in 1995 and 1997, respectively, reproductive success and number of active and depredated nests of 20 mated males in 1995 and another 20 different males in 1997 were monitored ( 2 males in 1995 and 5 males in 1997 whose nests were parasitized by Cuckoos were discarded from the analysis). Of those males, the exact day of laying of the first egg in the first clutch was known for 18 males in 1995 and 16 males in 1997. The age of the subjects was unknown.

Tail features were analyzed with respect to (1) male reproductive success: number of fledglings produced by each male for the whole season, (2) date of first egg laid: number of days from the day before the laying of the first egg in the first male's nest, and (3) the proportion of depredated nests: number depredated di- 
vided by number of active nests (a nest was considered to be depredated if all eggs or nestlings disappeared).

Four tail features were measured: (1) tail length, total area of (2) terminal white patches, and (3) subterminal black patches, and (4) fluctuating asymmetry (FA) in the area of black tail patches (difference between sums of right and left sides).

Tail length (measured with calipers, to the nearest $0.01 \mathrm{~mm}$ ) was the length of the longest tail feather (the longer of the two central tail feathers). Total area of white and of black tail patches (in $\mathrm{mm}^{2}$ ) was the sum of the 8 white and of the 10 black tail patches, respectively. To obtain area values, the patches were outlined with a thin pen on transparent plastic sheets. The outlines were scanned and the area of each one was calculated with the aid of Sigmascan software for Windows (Jandel Corporation, San Rafael, California). In relation to $\mathrm{FA}$ in the patch area, area difference between sum of patch areas (white and black separately) of right and left sides of the tail were obtained: only area difference of black patches, not white patches, conformed to a FA pattern, and because the area difference |Right - Left| obtained for the black patches did not change with their total area, the FA index used for this character is $|R-L|$ (Palmer 1994).

In order to detect a potential relationship between the analyzed tail features and body reserves, an index of individual condition was calculated: body weight $x$ tarsus length ${ }^{-3}$ for each male (with portable electronic balance and calliper, to the nearest $0.01 \mathrm{~g}$ and 0.01 mm, respectively) (Brown 1996). The repeatability of body measures and of the tail features (including FA of black tail patches) was high (intraclass correlations not lower than $0.93 ; P<0.001$ in all cases).

The study area was inspected every two days for new nests, number and condition of eggs or chicks, which male was "in charge" of each nest, whether the nest was successful or not, and the number of fledglings, if any, "flying from" each nest. From this information, the proportion of depredated nests and the total seasonal reproductive success were obtained for each male.

The relationship of tail features with male reproductive success, date of laying of first egg, and with the proportion of depredated nests was estimated with multiple linear regression in separate analysis for each year. When the analyzed model was statistically significant, the step-down backward elimination procedure was applied (Zar 1996).

The distribution of FA of black patches was normalized according to Swaddle et al. (1994). The transformation used was $\left(Y+\left(\lambda_{2}\right)^{\lambda_{1}}\right.$, where $\lambda_{1}$ is 0.3 and $\lambda_{2}$ is the value of the smallest asymmetry minus one ( $P>0.2$, Kolmogorov-Smirnov test). The proportion of depredated nests was arcsin transformed and the remainder variables transformed by $\log _{10}(X+1)$; none of the transformed variables deviated significantly from a normal distribution.

\section{RESULTS}

In relation to male reproductive success, multiple re gression of the four tail features on the total number of fledglings produced by males in a season was significant in both years (1995: $F_{4,15}=3.2, n=20, P<$ $\left.0.05 ; 1997: F_{4,15}=8.0, n=20, P<0.001\right)$. The stepdown elimination procedure showed a significant relationship with FA of subterminal tail black patches in $1995\left(F_{4,18}=9.3, n=20, P<0.01\right)$, and FA of subterminal tail black patches and total area of terminal white tail patches in $1997\left(F_{4,17}=13.3, n=20, P<\right.$ 0.001 ) (1995: $\log _{10}$ [number of fledglings] $=1.38-$ 0.58 standardized [FA of black tail patches]; 1997 : $\log _{10}$ [number of fledglings] $=-8.40-0.45$ standardized [FA of black tail patches] $+0.41 \log _{10}$ [area of white tail patches]). Apparently, males attain greater reproductive success the smaller the FA of their tails' black patches and the larger the total area of the white tail patches (Fig. 1).

Date of first egg laid (and presumably of mate acquisition) also was significantly dependent on the tail features in the two study periods (1995: $F_{4,13}=7.7, n$ $=18, P<0.003 ; 1997: F_{4,11}=3.4, n=16, P<0.05$ ), and more specifically with FA of black tail patches in the two years of study, and with tail length in one year (1995: $\log _{10}$ [date of first egg laid] $=19.1+0.76$ standardized [FA of black tail patches] - $0.34 \log _{10}$ [tail length]; $1997: \log _{10}$ [date of first egg laid] $=0.84$ +0.65 standardized [FA of black tail patches]).

Immediately after suffering nest predation, Rufous Bush Chats usually start a new nest. As a result, the number of active nests for each male varied from 1 to 6 (successive) nests in 1995 and from 1 to 4 in 1997 , and the number of depredated nests from 0 to 4 in both years. The multiple regression of the four tail features on the proportion of depredated to active nests also produced significant results, similar to those obtained for reproductive success (1995: $F_{4,15}=2.9, n=$ 20, $P=0.05 ; 1997: F_{4,15}=13.6, n=20, P<0.001$ ) [1995: arcsin (proportion of depredated nests) $=-1.10$ +0.62 standardized (FA of black tail patches); 1997: $\arcsin$ (proportion of depredated nests) $=15.92+0.49$ standardized (FA of black tail patches) $-0.44 \log _{10}$ (area of white tail patches)].

Reproductive success was strongly related to date of laying of the first egg in one of the two years of study (1995: $r_{\mathrm{s}}=-0.67, n=18, P<0.003 ; 1997: r_{\mathrm{s}}=$ $-0.33, n=16, P=0.22$ ), and with the proportion of depredated nests in the two years of study (1995: $r_{\mathrm{s}}=$ $-0.55, n=20, P<0.013 ; 1997: r_{\mathrm{s}}=-0.84, n=20$, $P<0.001$ ). Thus, the lower the nest predation and (with less certainty) the earlier the mating, the higher the male reproductive success.

The analyzed tail features did not correlate with each other at a significant level, except for total area of white patches vs. FA of black patches (Table 1). Correlations between the analyzed tail features and condition (body weight $\times$ tarsus length ${ }^{-3}$ ) were nonsignificant (Table 1).

\section{DISCUSSION}

Of the analyzed tail features, FA of the subterminal black patches shows the highest relationship with seasonal male reproductive success, date of mate acquisition, and with proportion of depredated nests. A significant relationship was found between tail length and date of mate acquisition, and between total area of the white terminal patches with male reproductive success, and with proportion of depredated nests. 


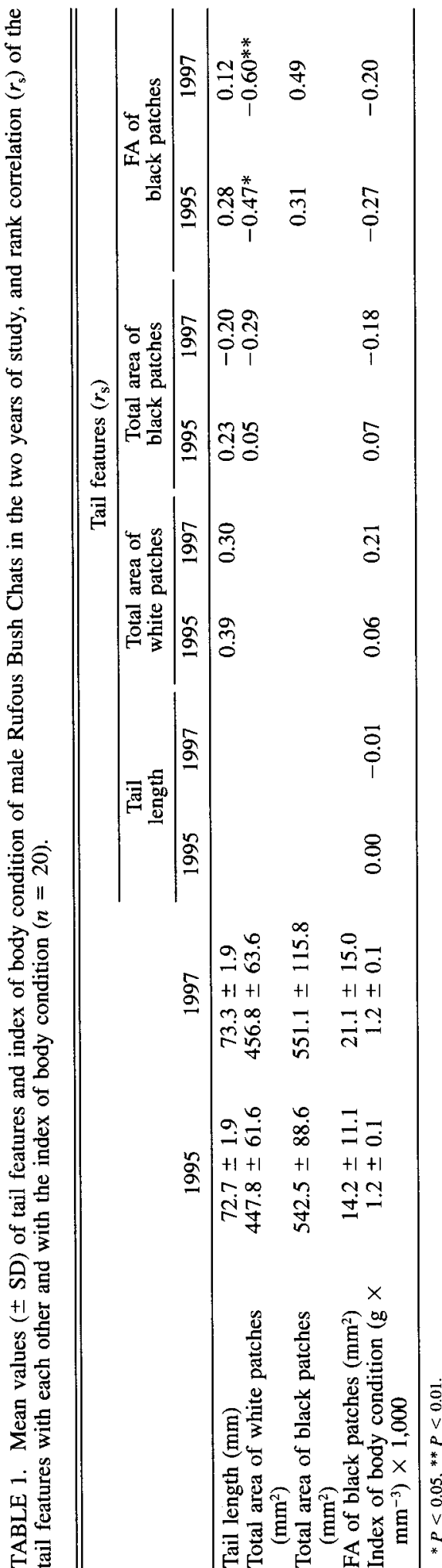

Perhaps a way to understand how these features may function is to consider that during the tail display (which occurs from less than $1 \mathrm{~m}$ up to $50 \mathrm{~m}$ from the receiver), the total area of the white patches contributes to conspicuousness, more so if we consider that the rest of the plumage coloration of Rufous Bush Chats is cryptic, and the presence of adjacent black patches is adding to contrast. A longer tail would obviously render those two features more visible.

As high reproductive success in our subjects appears related to early mating and to low proportion of depredated nests, and both variables are highly related to FA, we cannot determine which of the two is being affected by FA in the color pattern. The fact that the color patches are shown in tail display during aggressive encounters, courtship, and nest defense does not clarify whether the symmetric color pattern plays a role in sexual selection and/or diminishing nest predation.

If female choice of males with symmetrical visual tail-features occurs in Rufous Bush Chats (as is the case in other birds: Møller 1992, 1993, Swaddle and Cuthill 1994a, 1994b, Bennet et al. 1996, Fiske and Amundsen 1997), its straightforward nature (Wittenberger 1983) would be less time-consuming than if the choice would be based on a set of criteria. Time is apparently important, as early arrival to the breeding area and early mating usually contribute positively to reproduction in Rufous Bush Chats (present study) and other passerines (Lozano et al. 1996, Nyström 1997).

If females preferred symmetry in coloration, its function signaling high levels of developmental stability (Møller and Swaddle 1997) could provide the receiver with a nondeceptive signal of individual genetic quality, with no obvious costs to the sender.

In relation to nest predation, for FA in the contrasting black patches to be effective, it should function to attract the potential predator towards the bird (and away from the nest) during the distraction display, more easily than if the pattern were not symmetric. The Common Cuckoo, besides being a brood parasite of Rufous Bush Chats (Alvarez 1994a), also is a common predator of their nests, as well as a frequent receiver of their attacks and distraction displays (Alvarez 1994b). Among the potential nest predators in the study area (horseshoe snakes Coluber hippocrepis, Montpellier snakes Malpolon monspessulanus, ocellated lizards Lacerta lepida, weasels Mustela nivalis, domestic cats, and dogs), the Cuckoo is probably the only one with sufficient visual acuity to pay special attention to color patterns.

If predators are sensitive to very small asymmetries (Møller and Swaddle 1997), symmetric signals of contrast, combined with high conspicuousness in the tail display of Rufous Bush Chats, could perhaps attract them more easily towards the displaying bird. Both high conspicuousness and symmetric contrast, sometimes exhibited at very close range, could act together as a deflective mark (Cott 1940), attracting the predator and luring it away from the nest.

The pattern of erosion of the tail feathers supports the idea that conspicuous and contrasted black and white pattern and tail length help males to acquire a mate and/or lure predators away from the nest. The more intense abrasion of the apical white patches, 
some of them even vanishing at the end of the breeding season, is obviously related to their reduced resistance to abrasion, as they contain no melanin (Burtt 1979). In contrast, the melanin-protected black patches are hardly eroded. As a consequence, the apical white patches become smaller, and the tail length, as well as the conspicuousness of the whole pattern, are reduced at a time when they are not needed in mate acquisition and nest defense.

The fact that males in good condition are not better equipped with respect to the tail features related to reproduction may be the result of the index of condition used (body weight $\mathrm{x}$ tarsus length ${ }^{-3}$ ), which primarily measures body fat. Fat reserves should not be related to the potential to grow tail feathers (lack of relationship with tail length) or to the color pattern (total area of white patches and FA of black patches). Lack of a relationship of a similar index of body condition with FA of tail length and of other ornamental and non-ornamental traits also was found for the Red Junglefowl (Gallus gallus) by Kinball et al. (1997).

I thank M. Vázquez, B. Arrizabalaga, José and Juan Ayala, and J. Bernal for help in the field, and E. Aguilera, J. A. Amat, J. Cuervo, and T. Redondo for helpful comments. Financial support was provided by DGICYT (PB95-0110) and Junta de Andalucía (RNM 0105).

\section{LITERATURE CITED}

Alvarez, F. 1994a. A gens of Cuckoo Cuculus canorus parasitizing Rufous Bush Chat Cercotrichas galactotes. J. Avian Biol. 25:239-243.

Alvarez, F. 1994b. Cuckoo predation on nests of nearest neighbours of parasitized nests. Ardea 82: 269-270.

AlvaREZ, F. 1996. Variation in the song rate during the breeding cycle of the Rufous Bush Chat, Cercotrichas galactotes. Ardeola 43:49-56.

AlVAREZ, F. 1997. The functions of song and the spatial pattern of song production in the Rufous Bush Chat (Cercotrichas galactotes). Doñana, Acta Vert. 24:67-78.

ANDERSSON, M. 1982. Female choice selects for extreme tail length in a widowbird. Nature 299:818-820.

Andersson, M. 1994. Sexual selection. Princeton Univ. Press, Princeton, NJ.

BAKER, R. R., AND G. A. PARKER. 1979. The evolution of bird coloration. Phil. Trans. R. Soc. Lond. B 287:63-130.

BARNARD, P. 1990. Male tail length, sexual display intensity and female sexual response in a parasitic African finch. Anim. Behav. 39:652-656.

BennetT, A. T. D., I. C. CuthILl, J. C. PARTRIDGe, AND E. J. MAIER. 1996. Ultraviolet vision and mate choice in zebra finches. Nature 380:433-435.

Brown, M. E. 1996. Assessing body condition in birds. Current Ornithol. 13:67-135.

BuRTt, E. H. 1979. Tips on wings and other things, p. 75-110. In E. H. Burtt [ED.], The behavioral significance of color. Garland STPM Press, New York.

CotT, H. B. 1940. Adaptive coloration in animals. Methuen, London.
Cramp, S. 1988. The birds of the Western Palearctic. Vol. 5. Oxford Univ. Press, Oxford

Fiske, P., AND T. AMUNDSEN. 1997. Female bluethroats prefer males with symmetric colour bands. Anim. Behav. 54:81-87.

FitzPatRick, S., AND P. PRICE. 1997. Magpie tails: damage as an indicator of quality. Behav. Ecol. Sociobiol. 40:209-212.

KeIth, S., E. K. Urban, and C. H. Fry. 1992. The birds of Africa. Vol, IV. Academic Press, London.

Kinball, R. T., J. D. Ligon, And M. Merola-ZwaRTJES. 1997. Fluctuating asymmetry in Red Junglefowl. J. Evol. Biol. 10:441-457.

Kose, M., AND A. P. MøLler. 1999. Sexual selection, feather breakage and parasites: the importance of white spots in the tail of the Barn Swallow (Hirundo rustica). Behav. Ecol. Sociobiol. 45:430-436.

LóPez I., G. 1983. Datos sobre la nidificación del alzacola (Cercotrichas galactotes). Alytes 1:373392.

Lozano, G. A., S. Perreault, and R. E. Lemon. 1996. Age, arrival date and reproductive success of male American Redstart Setophaga ruticilla. J. Avian Biol. 27:164-170.

MøLlER, A. P. 1988. Female choice selects for male sexual tail ornaments in the monogamous swallow. Nature 332:640-642.

MøLler, A. P. 1992. Female swallow preference for symmetrical male sexual ornaments. Nature 357: $238-240$

MøLlER, A. P. 1993. Female preference for apparently symmetrical male sexual ornaments in the Barn Swallow Hirundo rustica. Behav. Ecol. Sociobiol. 32:371-376

Møller, A. P., AND J. P. SwaddLE. 1997. Asymmetry, developmental stability, and evolution. Oxford Univ. Press, Oxford.

NystRöm, K. G. K. 1997. Food density, song rate, and body condition in territory-establishing Willow Warblers (Phylloscopus trochilus). Can. J. Zool 75:47-58.

PALMER, A. R. 1994. Fluctuating asymmetry analyses: a primer, p. 335-364. In T. A. Markow [ED.], Developmental instability: its origins and evolutionary implications. Kluwer Academic Publishers, Dordrecht, Netherlands.

PäRT, T., AND A. Qvarnström. 1997. Badge size in Collared Flycatchers predicts outcome of male competition over territories. Anim. Behav. 54: 893-899.

Swaddle, J. P., AND I. C. Cuthill. 1994a. Female zebra finches prefer males with symmetric chest plumage. Proc. R. Soc. Lond. B 258:267-271.

Swaddle, J. P., And I. C. Cuthill. 1994b. Preference for symmetric males by female zebra finches. Nature 367:165-166

Swaddle, J. P., M. S. Witter, And I. C. Cuthill. 1994. The analysis of fluctuating asymmetry. Anim. Behav. 48:986-989.

Wittenberger, J. F. 1983. Tactics of mate choice, p. 435-447. In P. Bateson [ED.], Mate choice. Cambridge Univ. Press, Cambridge.

ZAR, J. H. 1996. Biostatistical analysis. Prentice Hall, Upper Saddle River, NJ. 